\title{
A FORMAÇÃO INICIAL DE PROFESSORES QUE ENSINAM MATEMÁTICA NO ENSINO FUNDAMENTAL E AS DIRETRIZES CURRICULARES NACIONAIS PÓS-LDB 9394/96
}

\author{
Kelvin Rafael Rodrigues de Oliveira ${ }^{1}$, Leny Rodrigues Martins Teixeira ${ }^{2}$ \\ ${ }^{1}$ Mestrando em Educação pela Universidade Estadual Paulista Júlio de Mesquita Filho - UNESP, Presidente Prudente, \\ SP. Professor de Matemática na Rede de Ensino Privada em Presidente Epitácio, SP. Coordenador de Qualificação na \\ Secretaria de Estado da Educação de Mato Grosso do Sul, MS. ORCID iD: https://orcid.org/0000-0002-9691-6368. E- \\ mail: kelvin rodrioliver1@hotmail.com. \\ ${ }^{2}$ Doutorado em Psicologia Escolar e do Desenvolvimento Humano pela Universidade de São Paulo - USP, SP. \\ Professora do Programa de Pós-Graduação em Educação da Universidade Estadual Paulista Júlio de Mesquita Filho - \\ UNESP, Presidente Prudente, SP. ORCID iD: https://orcid.org/0000-0003-4984-8187. E-mail: \\ lenyrmteixeira@gmail.com .
}

\section{RESUMO}

O presente estudo se insere no campo da formação dos professores que ensinam Matemática no Ensino Fundamental e tem como objetivo analisar a constituição dos cursos formadores desses professores Licenciatura em Pedagogia e em Matemática. Pesquisas publicadas a esse respeito indicam algumas lacunas na prática desses professores, em grande parte, devido a fatores relacionados à formação inicial. Neste sentidoé necessário compreender a estrutura desses cursos embasadas nas Diretrizes Curriculares Nacionais para a Formação de Professores desde a LDB 9394/96. O texto apresenta uma análise destes documentos - pré-requisito para compreender o processo de formação inicial - envolvendo estrutura e organização do currículo de formação, carga horáriade Matemática e/ou Educação Matemática, estágios curriculares e trabalho de conclusão de curso. A análise indica quea formação inicial de professores que ensinam Matemática apresenta enfoques diferentes para pedagogos e licenciados em Matemática,o que dificulta a continuidade do trabalho com matemática no Ensino Fundamental.

Palavras-chave:Formação de professores.Pedagogos.Licenciados em Matemática. Diretrizes Curriculares Nacionais.Matemática no Ensino Fundamental.

\section{INITIAL TRAINING OF TEACHERS WHO TEACH MATHEMATICS IN ELEMENTARY SCHOOL AND POST-LDB NATIONAL CURRICULUM GUIDELINES 9394/96}

\section{ABSTRACT}

This study is part of the field of training of teachers who teach Mathematics in Elementary School and aims to analyze the constitution of the courses of formation of these teachers - Degree in Pedagogy and Mathematics. Published researches on this subject indicate some gaps in the practice of these teachers, largely due to factors related to initial training. In this sense it is necessary to understand the structure of these courses based on the National Curricular Guidelines for Teacher Training since LDB 9394/96. The text presents an analysis of these documents - a prerequisite to understand the initial training process involving the structure and organization of the training curriculum, the workload of Mathematics and/or Mathematics Education, curricular internships and course completion work. The analysis indicates that the initial training of teachers who teach Mathematics presents different approaches for pedagogues and graduates in Mathematics, which makes it difficult to continue working with Mathematics in Elementary School.

Keywords: Teacher training. Pedagogues. Graduates in Mathematics. National Curricular Guidelines. Mathematics in ElementarySchool.

FORMACIÓN INICIAL DE LOS MAESTROS QUE ENSEÑAN MATEMÁTICAS EN LA ESCUELA PRIMARIA Y DIRECTRICES DEL PLAN DE ESTUDIOS NACIONAL DESPUÉS DEL LDB 9394/96 


\section{RESUMEN}

Este estudio forma parte del campo de la formación de losprofesores que enseñan matemáticas en la escuela primaria y tiene como objetivo analizar la constitución de los cursos de formación de estosprofesores - Licenciatura enPedagogía y Matemáticas. Lasinvestigaciones publicadas sobre este tema indicanalgunas lagunas en la práctica de estos maestros, debidoengran parte a factores relacionados con la formación inicial. En este sentido es necesario entender la estructura de estos cursos basadosenlasDirectrices Curriculares Nacionales para la Formación de Profesores desde el LDB 9394/96. Enel texto se presenta unanálisis de estos documentos -un requisito previo para comprenderelproceso de formación inicial- que incluye la estructura y la organización del plan de estudios de formación, la carga de trabajo de la enseñanza de las matemáticas y/o la educación matemática, lasprácticas curriculares y eltrabajo de finalización de los cursos. El análisis indica que la formación inicial de losprofesores que enseñan matemáticas presenta diferentes enfoques para los pedagogos y los graduados en matemáticas, lo que dificulta la continuación del trabajoconlas matemáticas en la educación primaria.

Palabras-clave: Formación de professores.Pedagogos. Licenciados en Matemáticas.Directricesdelplan de estudios nacional. Matemáticas em laescuela primaria.

\section{INTRODUÇÃO}

A formação de professores que ensinam Matemática no Ensino Fundamentaltem sido realizada em modalidades diferentes: no curso de Pedagogia para as séries iniciais e no curso de licenciatura em Matemáticapara os anos finais e Ensino Médio.

Desde sua criação em 1939,o curso de Pedagogiatem revelado vários problemas. 0 modelo inicial proposto para o curso propunha formação deum bacharel em Pedagogia, sem elementos que constituíssem ou caracterizassem sua identidade profissional como professor.

Somente a partir da década de 1990 dentro do período apontado por Silva (2006), como sendo o das propostas - houve muitas tentativas de melhorar o Curso de Pedagogia com a finalidade de contribuir para a constituição da identidade dopedagogo como professor.Para Brzezinski (1996), o adventoda Lei de Diretrizes e Bases de Educação Nacional (LDBEN) n 9394/96 traduz tais propostas, trazendo uma mudança significativa para a identidade do curso.

Com a aprovação da LDB 9394/96o curso de Pedagogia deveformar, habilitar professores e não especialistas, adotando assim a docência como base da identidade e formação deste profissional.

Para Silva (2006), a LDB 9394/96 trouxe novamente o curso de Pedagogia à pauta das discussões, e com ele, a questão da sua identidade, desta vez envolvida com novas questões, dentre as quais o currículo de formação para a docência e olugar das habilitações que formam os especialistas no curso.Emsíntese,analisar o processo de transformações ocorridas no Curso de Pedagogia, segundo Pinto (2006) mostra que uma das maiores modificações se deuquando o curso foi reconfigurado de bacharelado para licenciatura. Segundo o autor:

Desde sua criação em
1939, o curso contempla o
preparo dos profissionais
para o exercício da
docência, assim como para
os campos específicos de
atuação do pedagogo.
Porém, sua grade
curricular esteve sempre
mais centrada nesses
campos específicos da
pedagogia escolar e não
na docência, que sempre
apareceu de modo
secundário. Atualmente
ocorre uma situação
inversa: os cursos
centralizam o currículo em
torno da docência e
secundarizam os campos
de atuação do pedagogo
que configuram sua
identidade (PINTO, 2006,
p. 12).

Ao traçar uma linha cronológica do Curso de Pedagogia desde sua criação, percebe-se uma luta constante para caracterizar e identificar os pedagogos como docentes, apesar de seu currículo genérico. Segundo Silva (2006, p. 89):

[...] não há como negar a fragilidade que reveste $o$ curso de pedagogia e, 
também, a pedagogia enquanto campo de conhecimento. Não se pode negar, também, que esse campo vem se afirmando no que se refere ao reconhecimento de sua especificidade e que avanços significativos vêm sendo empreendidos quanto à definição de seu estatuto.

Embora não tenha em seu históricoosmesmosimpasses e desafios enfrentados pelo curso de Pedagogia, o curso de licenciatura em Matemática também passou por algumas configurações, natentativa de superar o modelo $3+1$ que configurava uma clara dualidade na relação entre conteúdosmatemáticos e os pedagógicos.

As primeiras licenciaturas em Matemática eram organizadas segundo o "modelo $3+1$ ", no qual, após três anos de estudos de Matemática, seguia um ano de estudos sobre didáticas e práticas. Esse modelo formava um professor a partir da concepção de que o ato de ensinar era visto, essencialmente, como o ato de transmitir conhecimento, logo, o futuro professor ainda em formação, passava pela etapa dos conhecimentos do conteúdo (três anos de Matemática) e depois pela etapa do aprender a transmitir esses conhecimentos (um ano de Didática e Práticas).

Assim como no curso de Pedagogia, a LDB 9394/96 foi um divisor de águas na licenciatura em Matemática, pois foi responsável por uma nova onda de debates acerca da formação docente no Brasil. A esse respeito, Diniz-Peireira, (1999, p. 121) esclarece que a LDB 9394/96 estipula como um dos deveres das universidades

[...] fixar os currículos dos seus cursos e programas, observadas as diretrizes gerais pertinentes (art. 53, inciso II). [...] Consequentemente, a figura do currículo mínimo, instrumento legal que determinou a organização dos cursos superiores no Brasil a partir da lei 5.540/71 e conduziu os concluintes desses cursos a diplomas profissionais,foi revogada com a nova lei.
Apesar de grande parte dos cursos de Licenciatura em Matemática não seguirem mais o formato 3+1, Moreira (2012) afirma que esse modelo não saiu das licenciaturas, pois, segundo o autor:

a lógica subjacente ao $3+1$ ainda permanece como a lógica estruturante desses cursos. O princípio basilar ainda é o mesmo: a separação entre as disciplinas de conteúdo e as disciplinas de ensino. $\mathrm{O}$ que mudou, de forma clara, foi a composição do grupo de disciplinas referentes ao ensino (que no $3+1$ era praticamente só Didática) e a proporção entre os tempos de formação referentes ao grupo dos conteúdos científicos e o grupo do ensino/ educação. Essa proporção agora gira em torno de 1:1. Uma vez internalizada e naturalizada a lógica de fundo do $3+1$, essa nova proporção pode parecer uma mudança bastante radical, mas, a meu ver, a questão crucial permanece intocada. (MOREIRA, 2012, p. 1140).

O autor explicita a dicotomia entre disciplinas específicas da Matemática e disciplinas de Ensino de Matemática a partir da concessão de que os currículos seriam divididos em dois blocos, a saber: o bloco da formação de conteúdos e o bloco da formação pedagógica. Essa estrutura curricular acontece de forma desarticulada e os conhecimentos são apreendidos de forma isolada sem integração entre eles em função do ensino de Matemáticaa ser praticado na escolabásica.

$O$ debate nacional acerca da formação docente ocorrido ao longo dos anos, conforme descreve Dourado (2015) tem se constituídocomo um campo marcado por certezas e incertezas na reorganização do sistema educacional nacional como um todo. Assim, vimos a necessidade de analisar os documentos que norteiam a estrutura desses cursos, a saber: 
Diretrizes Curriculares Nacionais para a Formação Inicial e Continuada dos Profissionais do Magistério da Educação Básica (2002, 2015 e 2019),Diretrizes Curriculares Nacionais para os Cursos de Matemática, Bacharelado e Licenciatura (2001) e Diretrizes Curriculares Nacionais para o curso de Pedagogia (2006)para posteriormente encontrar pontos convergentes e divergentes no que tange a formação dos professores que ensinam Matemática.

\section{Análise das diretrizes curriculares}

1.1 Diretrizes Curriculares Nacionais para a Formação de Professores da Educação Básica: Resolução CNE/CP 01 e 02/2002

Instaurada pós-LDB 9394/96, as Diretrizes Curriculares estão baseadas em Pareceres e Resoluções do Conselho Nacional de Educação. OParecer (CNE/CP) 9/2001,fundamenta as Resoluções CNE/CP 1/2002 e 2/2002, que definem as Diretrizes Curriculares Nacionais específicas para os cursos de licenciatura, apresentando ideias inovadoras por meio de propostas reflexivas.

O Parecer CNE/CP 9/2001 aponta que as diretrizes tinham por objetivo propor uma base comum de formação de professores, a serem desenvolvidas durante todo o processo de formação no Ensino Superior (BRASIL, 2001). Assim as DCNS são

[...] fruto de um longo processo de crítica, reflexão e confronto entre diferentes concepções sobre a formação docente e suas práticas, para 0 qual contribuíram o pensamento acadêmico, a avaliação das políticas públicas em educação, os movimentos sociais, as experiências inovadoras em andamento em algumas Instituições de Ensino Superior. Ela busca descrever o contexto global e o nacional da reforma educacional no Brasil, o quadro legal que Ihe dá suporte, e as linhas orientadoras das mudanças dos cursos de formação deprofessores. Com base no diagnóstico dos problemas detectados na formação

\begin{abstract}
dosprofessores, ela apresenta princípios orientadores amplos e diretrizes para uma política de formação de professores, para sua organização no tempo e no espaço e para a estruturação dos cursos (BRASIL, 2001, p. 6).
\end{abstract}

Dentre tais reflexões, elencamos algumas que, em especial, permearão as discussões acerca dos reflexos destes documentos nos cursos de licenciatura em Matemática e Pedagogia mais adiante:

- A carga horária total dos cursos de Formação de Professores da Educação Básica é estipuladaem 2.800 horas, sendo:

- (I) 1800 (mil e oitocentas) horas de aulas para os conteúdos curriculares.

- (II) 400 horas de Prática como Componente Curricular (PCC), presente em todo o períododo cursodistribuídas por todas as disciplinas de formação com o fim de oferecer ao licenciando melhor compreensão do ambiente e contexto escolar

- (III) 400 horas de estágio, a partir da segunda metade do curso;

- (IV) 200 horas de atividades acadêmico-científico-culturais.

Analisando alguns destes e outros elementos, a Resolução CNE/CP 02/2002propôs um olhar sobre $\mathrm{O}$ formato dos cursos de Licenciatura verificado pelo caráter de componente curricular atribuído às práticas. Assim, existe uma necessidade de integrar todas as disciplinas curriculares a fim de estabelecer uma práxis entre a formação e o contexto de sala de aula.

Dentre as mudanças estabelecidas, está a obrigatoriedade das 400 horas para o estágio curricular obrigatório e a criação de outras 400 horas de PCC (prática como componente curricular). Um longo processo se deu entre a publicação dessas DCN e sua efetiva incorporação.

Passados treze anos, com as DCN CNE/CP 2015 há uma ampliação do tempo mínimo de curso (3.200 horas), a articulação entre formação 
inicial e continuada, a incorporação de uma perspectiva interdisciplinar, além de várias orientações de inclusão das diversidades socioculturais na escola. Essas modificações nas diretrizes também representou um esforço do movimento nacional docente, através de suas associações, no sentido de situar os cursos de formação inicial dentro da realidade da escola básica para todos, condição amplamente debatida com a LDB 9394/1996 e legislação decorrente.

\subsection{Diretrizes Curriculares Nacionais para o curso de Pedagogia: Resolução no 1/2006}

Por meio do Parecer CNE/CP n 3/2006, são instituídas as Diretrizes Curriculares Nacionais para o Curso de Graduação em Pedagogia, licenciatura (BRASIL, 2006b). As DCNP ganham força, pois trazem incorporadas em si ideias e princípios daAssociação Nacional pela Formação dos Profissionais da Educação (ANFOPE).

Conforme a Resolução $n^{\circ}$ 1/2006, o curso de Pedagogia ganha uma nova estruturação, a saber: visa à docência, gestão e produção de conhecimento - por meio do incentivo à pesquisa. Em relação à sua configuração, a Resolução aponta que:

$$
\begin{aligned}
& \text { Art. 1o A presente } \\
& \text { Resolução } \begin{array}{r}
\text { institui } \\
\text { Diretrizes Curriculares }
\end{array} \\
& \text { Nacionais para o Curso de } \\
& \text { Graduação em Pedagogia, } \\
& \text { licenciatura, definindo } \\
& \text { princípios, condições de } \\
& \text { ensino e de aprendizagem, } \\
& \text { procedimentos a serem } \\
& \text { observados em seu } \\
& \text { planejamento e avaliação, } \\
& \text { pelos órgãos dos sistemas } \\
& \text { de ensino e pelas } \\
& \text { instituições de educação } \\
& \text { superior do país, nos } \\
& \text { termos explicitados nos } \\
& \text { Pareceres CNE/CP nos } \\
& \text { 5/2005 e 3/2006 (BRASIL, } \\
& \text { 2006b). }
\end{aligned}
$$

Em relação à formação, o Artigo $2^{\circ}$ define

que

A formação inicial para o exercício da docência na Educação Infantil e nos anos iniciais do Ensino Fundamental, nos cursos de Ensino Médio, na modalidade Normal e em

$$
\begin{array}{lr}
\text { cursos } & \text { deEducação } \\
\text { Profissional a arrea } & \text { a } \\
\text { deserviços e apoio escolar, } \\
\text { bem como em outras } \\
\text { áreas nas quais sejam } \\
\text { previstos conhecimentos } \\
\text { pedagógicos (BRASIL, } \\
\text { 2006b). }
\end{array}
$$

Por meio do documento, a docência assume uma nova dimensão para a formação deste profissional. Embora esteja habilitado também para atividades de gestão, o Curso de Pedagogia visa à formação de professores. $\mathrm{O}$ artigo $4^{\circ}$ corrobora esta afirmação ao incluir que "[...] as atividades docentes também compreendem participação na organização e gestão de sistemas e instituições de ensino." Desse modo, o documento relaciona qualquer atividade profissional no campo da educação com atividade docente, não limitando a atuação desse profissional apenas à docência.

As DCNPs enfatizam a questão da identidade do curso de Pedagogia, no sentido de considerar o pedagogo como um especialista do ensinoe/ou exercendo outras atividades de natureza pedagógica. Mesmo assim, segundo Libâneo (2006, p. 845-846),

$$
\begin{aligned}
& \text { Observa-se, desde logo, } \\
& \text { nesses artigos que as } \\
& \text { imprecisões conceituais } \\
& \text { resultam em definições } \\
& \text { operacionais muito } \\
& \text { confusas para a atividade } \\
& \text { profissional do pedagogo. } \\
& \text { De início, há uma definição } \\
& \text { explícita de que o objeto } \\
& \text { da regulamentação é um } \\
& \text { curso de licenciatura. } \\
& \text { Portanto, um curso que se } \\
& \text { situa na mesma categoria } \\
& \text { dos demais cursos de } \\
& \text { licenciatura da educação } \\
& \text { básica, deixando suposto } \\
& \text { que pode existir um curso } \\
& \text { de bacharelado em } \\
& \text { pedagogia, considerando- } \\
& \text { se a lógica da organização } \\
& \text { de cursos da universidade } \\
& \text { brasileira. }
\end{aligned}
$$

Ocurso visa atender a cinco modalidades de magistério definidas pela DCNP 1/2006, a saber: Educação Infantil, Anos iniciais do Ensino Fundamental, cursos de Ensino Médio, na modalidade Normal, cursos de Educação 
Profissional na área de serviços e apoio escolar e em outras áreas nas quais sejam previstos conhecimentos pedagógicos. Sobre issoLibâneo (2006) considera que o texto fazreferência apenas à docência na Educação Infantil e anos iniciais do Ensino Fundamental. Para o autor, faltam orientações quanto às modalidadescurriculares.

Em relação à matriz curricular do curso, a Resolução CNE/CP 1/2006 aponta que deve compor 3.200 horas de efetivo trabalho acadêmico, assim distribuídas:

I -2.800 horas dedicadas às atividades formativas como assistência a aulas, realização de seminários, participação na realização de pesquisas, consultas a bibliotecas e centros de documentação, visitas a instituições educacionais e culturais, atividades práticas de diferente natureza, participação em grupos cooperativos de estudos:

II - $\mathbf{3 0 0}$ horas dedicadas ao Estágio Supervisionado prioritariamente em Educação Infantil e nos anos iniciais do Ensino Fundamental,

contemplando também outras áreas específicas, se for o caso, conforme o projeto pedagógico da instituição;

III - 100 horas de atividades teórico-práticas de aprofundamento em áreas específicas de interesse dos alunos, por meio, da iniciação científica, da extensão e da monitoria. (BRASIL, 2006, p.2)

Em relação aos Estágios Supervisionados, a Resolução CNE/CP01/2006 especifica que

O estágio curricular a ser realizado, ao longo do curso, de modo a assegurar aos graduandos experiência de exercício profissional, em ambientes escolares e não-escolares que ampliem fortaleçamatitudes éticas, conhecimentos competências:

a) na Educação Infantil e nos anos iniciais do Ensino Fundamental,

prioritariamente;

b) nas disciplinas pedagógicas dos cursos de Ensino Médio, na modalidade Normal;

c) na Educação Profissional na área de serviços e de apoio escolar;

d) na Educação de Jovens e Adultos;

e) na participação em atividades da gestão de processos educativos, no planejamento,

implementação, coordenação, acompanhamento e avaliação de atividades e projetos educativos;

f) em reuniões de formação pedagógica

Percebe-se uma redução na carga horária em relação ao proposto pela DCN 02/2002: de 400 para 300 horas, o que impossibilita integralizar de forma efetiva e qualitativa essa carga horária, tendo em vista a vasta gama de atividades atreladas aos conhecimentos curriculares presentes no curso de Pedagogia. Assim, a Resolução CNE/CP 01/2006 gera um descompasso em relação ao proposto pela Resolução DCN/CP 02/2002 por reduzir a carga horária dos Estágios, tendo em vista que essas atividades no curso visam, dentre outros, a aspectos da prática nos anos iniciais do Ensino Fundamental.

Quanto aos aspectos do ensino, o Artigo $4^{\circ}$ da Resolução CNE/CP 01/2006,ao mencionar os objetivos da formação de professores pedagogos para o Ensino fundamental, aponta que as atividades docentes implicam: "VI: ensinar Língua Portuguesa, Matemática, Ciências, História, Geografia, Artes, Educação Física, de forma interdisciplinar e adequada às diferentes fases do desenvolvimento humano;" (BRASIL, 2006). Em relação ao ensino de Matemática, a formação fica comprometida tendo em vista o inchaço curricular e a redução na carga horária dos Estágios Curriculares para 300 horas, 
impossibilitando o maior contato com a realidade da escola.

Desse modo, a formação dos Licenciados em Pedagogia tem se constituído grande desafio, pois remete às discussões apontadas no inicio desta seção sobre as especificidades desse profissional.

\subsection{Diretrizes Curriculares Nacionais para a Formação de Professores da Educação Básica: Resolução CNE/CP 02/2015}

A Resolução CNE/CP 02/2015 definiu as Diretrizes Curriculares Nacionais para a formação inicial em nível superior (cursos de licenciatura, cursos de formação pedagógica para graduados e cursos de segunda licenciatura) e para a formação continuada.

Segundo Dourado (2015), a Resolução CNE/CP 02/2015 aponta algumas questões relevantes acerca da formação dos profissionais do magistério. Para o autor,

[...] as novas DCNs enfatizam a necessária organicidade no processo formativo e sua institucionalização ao entender que o projeto de formação deve ser elaborado e desenvolvido por meio da articulação entre a instituição de educação superior e o sistema de ensino e instituições de educação básica, envolvendo a consolidação de Fóruns Estaduais e Distrital Permanentes de Apoio à Formação Docente, em regime de cooperação e colaboração. Tais questões implicam novos horizontes à dinâmica formativa dos profissionais do magistério da educação básica, pois a garantia do direito à educação a grupos e sujeitos historicamente marginalizados exige transformação na forma como as instituições de educação básica e superior estruturamseus espaços e tempos, suas regras e normas, incorporam novos materiais e recursos pedagógicos. (DOURADO, 2015, p. 307).

Nela se encontra todo um capítulo destinado à valorização dos profissionais do magistério (Capítulo VII). É forte ainda, neste documento, o cuidado com a Formação Inicial e Continuada. Estes termos constam no título de quatro dos oito capítulos das Diretrizes de 2015.

No que tange especificamente à formação inicial para os profissionais do magistério na Educação Básica, em nível superior, o capítulo IV apresenta detalhadamente quais são esses cursos: cursos de graduação de licenciatura; cursos de formação pedagógica para graduados não licenciados; cursos de segunda licenciatura. Assim, o documento explicita que a instituição formadora precisa definir no seu projeto institucional as formas de desenvolver a formação inicial destes profissionais.

A estrutura curricular dos cursos de formação inicial de professores em nível superior é prevista no capítulo $V$. $O$ documento apresenta um conjunto de conteúdos considerados necessários para a composição curricular e estrutura-os em eixos, a saber: conteúdos específicos das áreas do conhecimento, objeto da transposição didática do professor, conteúdos didático-pedagógicos de acordo com a etapa ou modalidade de ensino, conteúdos de filosofia, política e fundamentos da educação.

O documento apresenta o currículo como sendo:

o conjunto de valores propícios à produção e à socialização de significados no espaço social e que contribui para a construção da identidade sociocultural do educando, dos direitos e deveres do cidadão, do respeito ao bem comum e à democracia, às práticas educativas formais e não formais e à orientação para o trabalho (BRASIL, 2015, p.2).

Ainda segundo o Artigo $13, \S 2^{\circ}$, os cursos de formação deverão garantir nos currículos conteúdos específicos da respectiva área de conhecimento ou interdisciplinares, seus 
fundamentos e metodologias bem como conteúdos relacionados aos fundamentos da educação, formação na área de políticas públicas e gestão da educação, seus fundamentos

e metodologias, direitos humanos, diversidades étnico-racial, de gênero, sexual, religiosa, de faixa geracional, Língua Brasileira de Sinais (Libras), educação especial e direitos educacionais de adolescentes e jovens em cumprimento de medidas socioeducativas (BRASIL, 2015, p.11).

Aestrutura do currículo deve contemplar carga horária mínima de 3.200 horas de efetivo trabalho acadêmico, em cursos com duração de, no mínimo quatro semestres, sendo:

- 400 horas de Prática como Componente Curricular (PCC), distribuídas ao longo do curso;

- 400 horas dedicadas ao estágio supervisionado, na área de formação e atuação na educação básica, contemplando também outras áreas específicas, se for 0 caso, conforme o projeto de curso da instituição (BRASIL, 2015)

- 2.200 horas de atividades formativas;

- 200 horas de atividades teóricopráticas que visem o aprofundamento em áreas específicas de interesse dos estudantes, conforme núcleo III (BRASIL, 2015a);

Ao tratar da carga horária dos cursos de formação inicial de professores, a Resolução menciona a todoo momento a perspectiva atribuída às relações entre teoria e prática. Essa relação, segundo o documento, articula os vários eixos curriculares, qualificando ainda mais a formação desses sujeitos. Além disso, se compararmos aspectos relacionados à carga horária evidencia-se que, na Resolução $\mathrm{CNE} / \mathrm{CP}$ 02/2002 para a Resolução CNE/CP 02/2015, existe um aumento da carga horária especificamente no que tange as atividades articuladas à prática que incluem iniciação científica, iniciação à docência, extensão, dentre outras.

Partindo da pressuposta valorização da relação teoria-prática presente na Resolução CNE/CP 02/2015, existe um avanço significativo quanto à formação matemática oferecida pelos cursos superiores de licenciatura em Matemática. Dada a articulação entre os eixos curriculares, pesquisa, ensino e extensão, é concebível que a formação se construa em um ambiente favorável à apreensão e construção dialógica dos conhecimentos necessários à docência.

O Artigo 22 da Resolução CNE/CP no 2, de 10 de julho de 2015 inicialmente indicava o prazo de dois anos para que os cursos de formação de professores em funcionamento se adequassem ao novo normativo. Apesar disso, mesmo antes de vencer o prazo ora determinado, em 2017 foi protocolado junto ao CNE um documento conjunto da Secretaria de Educação Superior (SESu), da Secretaria de Educação Básica (SEB) e do MEC contendo proposta de alteração do prazo. Outras Instituições Federais de Ensino Superior também apresentaram solicitações a fim de prolongar este prazo. Até o presente momento muitas instituições ainda não se adequaram à Resolução e mesmo assim, em dezembro de 2018, o MEC apresentou a Base Nacional Comum da Formação dos Professores da Educação Básica visando revisar as Diretrizes dos Cursos de Pedagogia e Licenciaturas para alinhá-los àBase Nacional Comum Curricular (BNCC). Em dezembro de 2019, o CNE aprovou o Parecer 22/2019, revogando a Resolução no 2/2015.Sendo assim, como a maioria dos cursos não havia se adequado à Resolução CNE/CP no 2, de 1 o de julho de 2015, resulta que tais cursosatualmente ainda estão regulados pelaResolução CNE/CP 02/2002. Algumas exceções se devem a Deliberações de Conselhos Estaduais de Educação.

\subsection{Diretrizes Curriculares Nacionais para a Formação de Professores da Educação Básica: Resolução CNE/CP 02/2019}

A Resolução CNE/CP $\mathrm{n} \cong 2$, de 20 de dezembro de 2019 - define as Diretrizes Curriculares Nacionais para a Formação Inicial de Professores para a Educação Básica e institui a Base Nacional Comum para a Formação Inicial de Professores da Educação Básica (BNC-Formação). A nova resolução foi elaborada sem diálogo com 
as instituições formadoras, faculdades de educação das universidades públicas e programas de pós-graduação em Educação - que participaram ativamente no processo de elaboração dos Pareceres anteriores.Em seu Artigo 30, a Resolução CNE/CP 2/2019 esclarece que "entrará em vigor na data de sua publicação, ficando revogada a Resolução CNE/CP no 2, de 1응 de julho de 2015" (BRASIL, 2019).

Nesta resoluçãoa valorização do magistério, ao menos em termos textuais, converte-se em um item do Artigo 60 "II - a valorização da profissão docente, que inclui o reconhecimento e o fortalecimento dos saberes e práticas específicas de tal profissão;". Nenhum dos nove capítulos destasdiretrizestrazem como título o termo Formação Inicial e/ou Formação Continuada.

$O$ documento, de caráter eminentemente técnico/tecnicista, não faz referência a nenhum estudo ou pesquisa elaborados pelas universidades nacionais. As referências são dadas pelos organismos internacionais ou de imprensa além de Movimentos/Fundações/organizações privadas ligadas ao Governo Federal.

Quanto à Organização Curricular dos Cursos Superiorespara a Formação Docente, a Resolução em seu capítulo 3, aponta que:

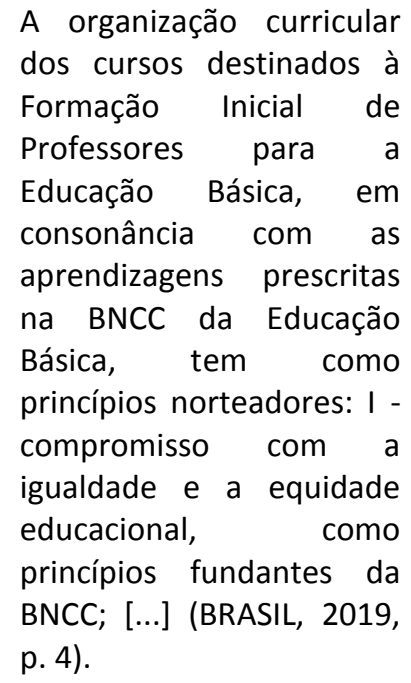

Quanto aos fundamentos pedagógicos, os cursos devem ter:

\begin{abstract}
ao futuro professor aprendizagens

significativas

contextualizadas em uma abordagem didáticometodológica alinhada com a BNCC, visando ao desenvolvimento da autonomia, da capacidade de resolução de problemas, dos processos investigativos e criativos, do exercício do trabalho coletivo e interdisciplinar, da análise dos desafios da vida cotidiana e em sociedade e das possibilidades de suas soluções práticas; (BRASIL, 2019, p. 5).
\end{abstract}

O documento explicita a forma como deve acontecer a formação do professor e, em vários momentos, aponta a BNCC como documento norteador para o Currículo e as atividades relacionadas à formação. Trata da autonomia garantida ao professor, mas a uma base que dita como se dá sua formação e consequentemente, sua prática.

Sobre essa questão, aAssociação Nacional de Pós-Graduação e Pesquisa em Educação (ANPED)em posição acerca da DCN 2/2019, declara:

Considera-se que centrar a formação de professores brasileiros somente na BNCC constitui um reducionismo sem precedentes na história da educação nacional, principalmente porque não prevê um perfil profissional voltado para o desenvolvimento de sua autonomia com capacidade de tomar decisões e dar respostas aos desafios que encontra na escola (ANPED, 2019, p. 3).

Com relação à carga horária total do curso, a Resolução CNE/CP 2/2019 estabelece que:

Todos os cursos em nível superior de licenciatura, destinados à Formação Inicial de Professores para a Educação Básica, serão 
organizados em três grupos, com carga horária total de, no mínimo, 3.200 (três mil e duzentas) horas, e devem considerar o desenvolvimento das competências profissionais explicitadas na BNCFormação, instituída nos termos do Capítulo I desta Resolução (BRASIL, 2019, p. 6).

Em relação aos saberes específicos, 1.600 horas são destinadas a esse eixo e organizadas do seguinte modo: componentes curriculares, componentes interdisciplinares ou áreas de estudos, nos termos do respectivo Projeto Pedagógico do Curso (PPC). Quanto às Práticas como Componente Curricular (PCC), o documento define que serão:

$$
\begin{aligned}
& \text { [...] } 800 \text { horas para a } \\
& \text { prática pedagógica deve } \\
& \text { estar intrinsecamente } \\
& \text { articulada, desde o } \\
& \text { primeiro ano do curso, } \\
& \text { com os estudos e com a } \\
& \text { prática previstos nos } \\
& \text { componentes curriculares, } \\
& \text { e devem ser assim } \\
& \text { distribuídas: } 400 \\
& \text { (quatrocentas) horas de } \\
& \text { estágio supervisionado, } \\
& \text { em ambiente de ensino e } \\
& \text { aprendizagem; e } 400 \\
& \text { horas, ao longo do curso, } \\
& \text { entre os temas dos Grupos } \\
& \text { I e II (BRASIL, 2019, p. 9). }
\end{aligned}
$$

Embora se tenhamantido a carga horária das atividades de PCC, o condicionamento à BNCC ainda fica explícito ao longo de todo o documento. Além disso, o caráter pragmático atribuído à formação pela Resolução de 2019 gera incompreensões quanto a alguns elementos quando comparados ao documento anterior (DCN 2/2015). Questões tais como tema transversal, Educação Sexual e valorização docente sequer são apontadas no documento.

Diante desses avanços e retrocessos, como ficou a formação do professor que ensina Matemática - pedagogos e licenciados em Matemática? Quais pontos presentes nestes documentos contribuem para uma formação efetiva frente aos desafios à formação desses professores?
A seguir, analisaremos alguns aspectos intrínsecos à formação desses profissionais presentes nas DCNs, ora analisadas, a partir de pesquisas realizadas neste sentido.

\section{A formação do professor que ensina Matemática frente às DCNs}

As alterações nas Diretrizes Curriculares desde a LDB 9394/96 reconfiguraram os Cursos de formação de professores, gerandomuitas discussões e debates acerca da estrutura desses cursos.Apósa apresentação das Diretrizes Curriculares pós-LDB (2002 a 2019), passamos a abordar a questão do Currículo de Formação de Professores que ensinam Matemática no Ensino Fundamental, ou seja, como se dá a formação matemática desses professores, e a relação entre a teoria e prática proposta pelasDCNsevivenciada nesses cursos.Para a análise dessa questão, nos ateremos às Resoluções de 2002 e 2015, dado que a Resoluçãode 2019 ainda nãoentrouemvigor.

\subsection{Uma análise da formação Matemática no curso de Pedagogia e na Licenciatura em Matemática}

\subsubsection{O Curso de Pedagogia}

O curso de Pedagogia possui um currículo caracterizado pela formaçãoem várias áreas do conhecimento, como a Matemática, História, Geografia, Língua Portuguesa e Ciências.

Segundo Curi (2004), 90\% dos cursos de Pedagogia priorizam questões metodológicas como essenciais à formação desse profissional, mesmo que as disciplinas apresentem carga horária reduzida. A autora aponta ausência de indicaçõesde que esses professores vivenciem pesquisa em Matemáticae referências aos fundamentos da Matemática. Além disso, esses professores têm poucas oportunidades para a formação matemática que possa fazer frente às exigências da Matemática escolar. A autora ainda afirma que nas grades curriculares dos Cursos de Pedagogia raramente são encontradas disciplinas voltadas à formação matemática específica. Dessa forma, os pedagogoscompreendem pouco, as novas abordagens apresentadas em documentos curriculares de matemática. Analisando a ementa e matriz curricular de 36 cursos de pedagogia a autora conclui:

É possível considerar que os futuros professores concluem cursos de formação sem 
conhecimentos de conteúdos matemáticos com os quais irão trabalhar tanto no que concerne a conceitos quanto a procedimentos, como também da própria linguagem matemática que utilizarão em sua prática docente. Em outras palavras, parece haver uma concepção de que o professor polivalente não precisa 'saber Matemática' e que basta saber como ensiná-la (CURI, 2004, p. 76-77).

Gatti e Nunes (2009) analisaram a ementa de 71 cursos de Pedagogia situados nas cinco regiões do país, abrangendo os anos 2001, 2004 e 2006. Os resultados apontaram que as instituições formadoras de professores se limitam a formar os professores com base em fundamentos deFilosofia, Sociologia, Psicologia e outros campos, dedicando para este fim $40 \%$ das disciplinas. Existe uma preocupação muito grande com as questões estruturais e históricas da Educação compouco espaço para os aspectosdidáticos do trabalho docente. As autoras explicitam a desconexão entre teoria e prática presentes nestes cursos e automaticamente, o despreparo desses profissionais para a realidade em sala de aula. Em relação a essa desconexão, Gatti e Nunes (2009, p. 24) indicam que o grupo de disciplinas formado pelas:

Didáticas Específicas, Metodologias e Práticas de Ensino (o "como" ensinar) representa $20,7 \%$ do conjunto, e apenas $7,5 \%$ das disciplinas são destinadas aos conteúdos a serem ensinados nas séries iniciais do ensino fundamental, ou seja, ao "o quê" ensinar.

Para as autoras, essa situação em relação às disciplinas especificamente voltadas para a formação matemática merece nossa atenção. Curi (2004, 2008), assim como Gatti e Nunes (2009) apontamque essas disciplinas representam menos de $4 \%$ da carga horária total do curso de Pedagogia (3.200h) e enfatizam prioritariamente aspectos metodológicos, ou seja, aprender a ensinar Matemática, como se ensinar pudesse ocorre sem saber Matemática.

Em relação aos conteúdos estudados, Curi (2004, p.12), aponta que:

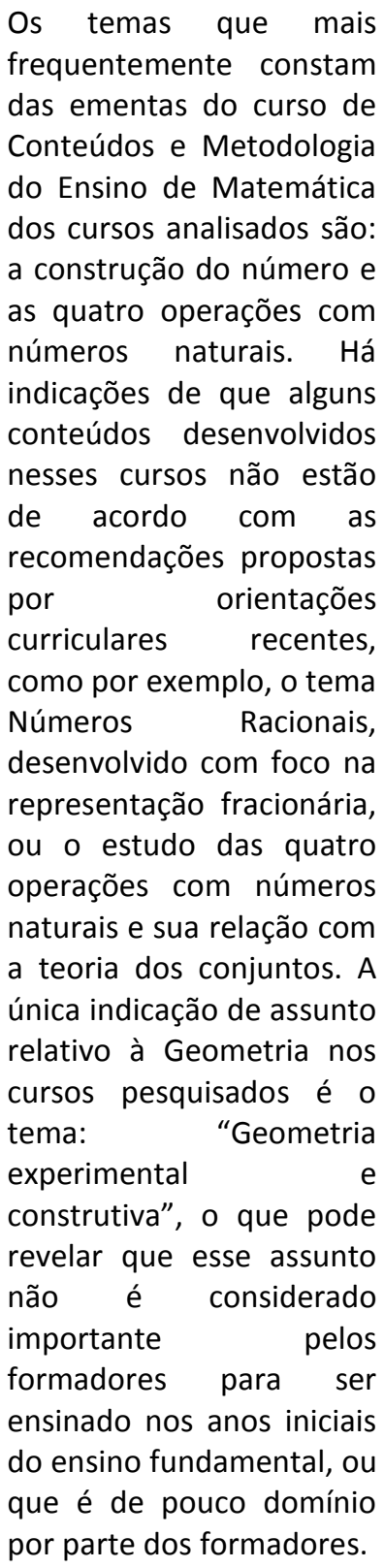

A partir dos apontamentos de Curi (2004) percebemos um distanciamento muito grande dos currículos presentes nesses cursos, dado o queos Parâmetros Curriculares Nacionais - PCN para o ensino da Matemática (BRASIL, 1997, p. 55), naquele momento, prescreviampara o currículodesta disciplina

[...] estabelecer relações que os aproximam de novos conceitos (como o de número racional, por exemplo), aperfeiçoam procedimentos conhecidos (contagem, medições) e 
constroem novos (cálculos envolvendo

proporcionalidade, por exemplo). [...] ampliar idéias e procedimentos relativos a contagem, comparação, ordenação, estimativa e operações que os envolvem. Ampliar ideias e procedimentos relativos a contagem, comparação, ordenação, estimativa e operações que os envolvem. [...]situações-problema cujas soluções não se encontram no campo dos números naturais, possibilitando, assim, que eles se aproximem da noção de número racional, pela compreensão de alguns de seus significados (quociente, parte-todo, razão) e de suas representações,

fracionária e decimal.

Vinte e um anos mais tarde, é publicada a versão final da Base Nacional Comum CurricularBNCC (2018) para o Ensino Fundamental priorizando, dentre outros aspectos, a articulação entre Aritmética, Geometria, Álgebra, Probabilidade e Estatística para que o aluno possa transitar entre diferentes conhecimentos e estabelecer, por si mesmo, relações entre eles. Os objetos de estudo propostos na BNCC não são muito diferentes dos propostos pelos PCNs, embora a organização do currículo se estruture sob a forma de competências e habilidades. A esse respeito, o documento trata de deixar claro que:

Assim, espera-se que eles desenvolvam a capacidade de identificar oportunidades de utilização da matemática para resolver problemas, aplicando conceitos, procedimentos e resultados para obter soluções e interpretá-las segundo os contextos das situações. A dedução de algumas propriedades e averificação de conjecturas, a partir de outras, podem ser estimuladas, sobretudo ao final do Ensino Fundamental (BRASIL, 2018, p.265).

Para atender às especificidades presentes nos currículos oficiais, é necessário que o professor aprenda sobre o desenvolvimento do pensamento lógico-matemático, sobre o trabalho com os processos mentais básicos e prénuméricos, como comparação, correspondência, classificação e outros (LORENZATO, 2011) e aprenda noções no campo dos números, operações, noções de grandeza, medida, espaço e forma (BRASIL, 1997), assim como os processos de pensamento envolvidos na construção desses conteúdos.

De qualquer forma, o trabalho com os conteúdos prescritos para o currículo de Matemática do Ensino Fundamental, tem sérias dificuldades considerando a carga horária de 60 ou 80 horas que é o tempo médio destinado às disciplinas de Matemática nos cursos de Pedagogia. As pesquisas de Passos e Nacarato (2018, p.131) corroboram essa afirmação, pois segundo as autoras,

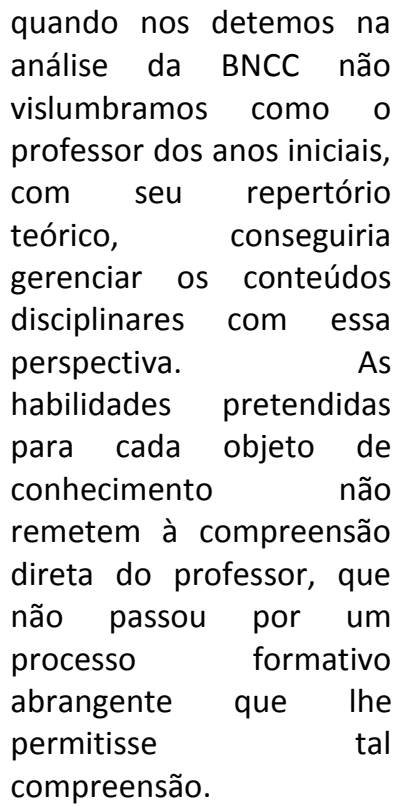

As pesquisas supracitadasapontam que a formação do professor não consiste em apenas aprender "como se ensina", mas também "o que se ensina", "porque se ensina". É importante que o conhecimento pedagógico esteja articulado aoconhecimento sobre o conteúdo a ser ensinado. Assim, verifica-se que não só a carga horária destinada aos conhecimentos matemáticos é insuficiente para fornecer condições para a atuação docente frente às 
especificidades do ensino de Matemática nos anos iniciais do Ensino Fundamental, assim como a forma como tais conteúdos seintegramnocurrículo.

A seguir, apresentaremos uma análise dos Cursos de Licenciatura em Matemática a partir das mesmas perspectivas da análise anterior. Objetiva-se compreender como as disciplinas estão organizadas e qual a relação entre teoria e prática presentes nestes cursos a partir de pesquisas já realizadas neste âmbito.

\subsection{0 curso de Licenciatura em Matemática}

Para Sacristán (2000), é essenciala discussão curricular nos cursos de Licenciatura, pois é o professor que vai pôr em prática o que está sendo determinado nos documentos curriculares. Assim, é importante refletir acerca do que está sendo abordado nos cursos de licenciatura em Matemática, não sóquanto aos conteúdosrelacionados às etapas de ensino que oslicenciandosatenderão, como àexistência ou não de consonância entre os temas propostos nas matrizes curriculares dos cursos superiores eosda educação básica.

Segundo as Diretrizes Curriculares Nacionais para os cursos de Licenciatura em Matemática (CNE/CES 1.302/2001), a organização dos currículos das instituições de Ensino Superior (IES) deve contemplar os conteúdos comuns a todos os cursos de Matemática, a saber: Cálculo Diferencial e Integral, Álgebra Linear, Fundamentos de Análise, Fundamentos de Álgebra, Fundamentos de Geometria e Geometria Analítica.

Quanto à parte comum, o Parecer CNE/CES 1.302/2001 (2001, p.6) indica que:

$$
\begin{aligned}
& \text { deve ainda incluir: a) } \\
& \text { conteúdos matemáticos } \\
& \text { presentes na educação } \\
& \text { básica nas áreas de } \\
& \text { Álgebra, Geometria e } \\
& \text { Análise; b) conteúdos de } \\
& \text { áreas afins à Matemática, } \\
& \text { que são fontes } \\
& \text { originadoras de problemas } \\
& \text { e campos de aplicação de } \\
& \text { suas teorias; c) conteúdos } \\
& \text { da Ciência da Educação, da } \\
& \text { História e Filosofia das } \\
& \text { Ciências e da Matemática. }
\end{aligned}
$$

A discussão acerca da formação de professores de Matemática se concentra principalmente no currículo de formação, em especial nas disciplinas de educação matemática presentes nestes cursos, pois o currículo é caracterizado por "uma práxis que envolve o domínio do conteúdo específico (a matemática) e o domínio de ideias e processos pedagógicos relativos à transmissão/assimilação e/ou à apropriação/construção do saber matemático escolar" (FIORENTINI; LORENZATO, 2006, p. 5).

A esse respeito, os estudos de Shulman (1986) sobre os conhecimentos dos professores, defende a articulação entre os conhecimento dos conteúdos específicos, conhecimento pedagógico do conteúdo (no ensino) e o conhecimento curricular. Para o autor, esses conhecimentos são construídos na prática do professor, ou seja, a partir dos desafios encontrados na prática docente. Neste sentido, é necessário compreender que para ensinar Matemática, não é suficiente apenas dominar o saber curricular, é preciso articular o saber pedagógico com o saber do conteúdo de ensino.Muitos cursos de licenciatura em Matemática ainda têm em seu currículo a ausência de disciplinas que articulemsaberes técnico-científico e saberes pedagógicos.

Revisitando a pesquisa de Gatti e Nunes (2009), em cursos ainda regidos pela Resolução CNE/CP 01 e 02/2001, percebemos que a distribuição dos conteúdos de formação do professor de Matemática se dá de forma muito parecida em diversos cursos, indicando que alguns conteúdos são abordados como essenciais à formação e outros são explanados de forma superficial, quando são trabalhados. Para as autoras, existem três tipos de licenciatura em Matemática:

10 os que investem em disciplinas de formação específica em Matemática, contemplando conteúdos discriminados nas Diretrizes Curriculares para Cursos de Matemática apenas para cursos de Bacharelado. São cursos que estudam de maneira bem aprofundada os conteúdos de Álgebra, Análise (incluem disciplinas intituladas por Equações Diferenciais, Variáveis Complexas, Cálculo Vetorial e Topologia) e Geometria - abordando Geometria das 
O exame dos currículos de licenciatura em Matemática realizado pelas autoras mostra que:

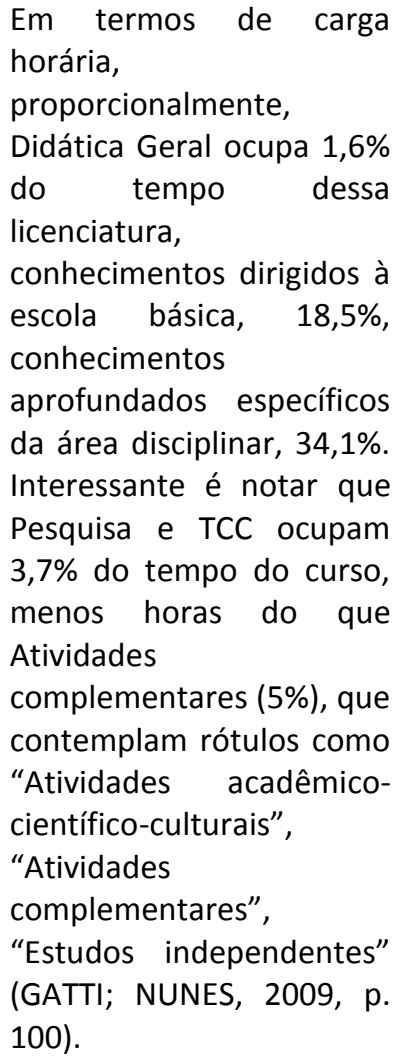

Além do problema daproporção entre conteúdos específicos e pedagógicos, constitui um desafio para os cursos de licenciatura em Matemática a realização de atividades que possibilitem a relação entre os conhecimentos pedagógicos e didáticos dos conteúdos, conforme foi constatado no trabalho de Batista (2018, p. 253-254):

Há preocupação com as disciplinas isoladamente e não com o projeto como um todo, resultando em pouca articulação entre aspectos pedagógicos e disciplinares. Também existe a concepção difusa sobre o perfil do professor da Educação Básica, em que os formadores apresentaram aspectos didáticos e atitudinais como características principais de um professor de Matemática, contradizendo a fala sobre a ligação entre os conteúdos das disciplinas que ministram com a escola básica que se circunscreve ao uso de procedimentos.

Sobre esse aspecto da formação, Fiorentini et al. (2002, p. 54) apontam alguns problemas:

[...] desarticulação entre teoria e prática, entre formação específica e pedagógica e entre formação e realidade escolar; menor prestígio da licenciatura em relação ao bacharelado; ausência de estudos históricofilosóficos

epistemológicos do saber matemático;

predominância de uma abordagem técnico-formal das disciplinas específicas; falta de formação teóricoprática em Educação Matemática dos formadores de professores.

Algumas dessas atividades estão relacionadas aos Estágios Supervisionados e Trabalho de Conclusão de Curso que, em geral, deveriam garantir a articulação entre os eixos curriculares presentes nos currículos de licenciatura em Matemática.

Sobre o Estágio Supervisionado obrigatório, a pesquisa de Gatti e Nunes (2009) aponta a dissonância existente entre esta ação e - currículo. Sobre a importância do Estágio Supervisionado, Cyrino e Passerini (2009, p. 126) indicam que:

[...] o Estágio representa o contato com os múltiplos elementos que constituem a prática educativa, possibilitando uma discussão e uma reflexão sobre 0 processo educativo nas escolas. 0 contato gradativo e sistemático com o futuro campo de trabalho, com as situações escolares em diferentes níveis de ensino, ao longo de todo curso de formação inicial, pode possibilitar ao futuro professor reconhecer limites e potencialidades 
das práticas educativas observadas; analisar, construir e testar possíveis ações para remediar ou suprir as necessidades práticas com as quais entrará em contato em sua futura prática profissional.

O Estágio Supervisionado insere o professor em formação no campo da prática profissional. É o momento em que oprofessorpode ter a oportunidade de passar pela experiência da docência e lhe é possibilitado interagir com os agentes escolares e alunos, bem comoconhecer aspectos mais gerais do ambiente escolar. Para Gatti e Nunes (2009, p. 109),

Nos projetos e currículos não fica claro como ocorre a integralização das horas obrigatórias de estágios nas diversas instituições. Algumas instituições não distinguem as atividades destinadas à Prática de Ensino e ao Estágio. Os processos de supervisão dos estágios e sua validação também não são objeto de tratamento explicitado.

A dissonância entre o previsto legalmente e o praticado nos Estágios Supervisionados faz com que o aluno, futuro professor, tenha uma experiência pobre nos estágios.Tal fato, no geral, se deve a vários fatores: constitui uma experiência solitária, acompanhada por uma supervisão burocrática, não constituiobjeto de reflexão coletivasobre a prática o que impossibilita a relação teoria e prática. Assim, os estágios se mostram apenas mais uma exigência prescrita no currículo do que um elementoretroalimentadordo curso que realmente proporciona uma formação mais completa para o futuro professore o prepare para os desafios a serem vivenciados

Ao longo dos anos, desde a LDB 9394/96, algumas medidas, ações e propostas têm sido feitas do ponto de vista das políticas de formação de professores - tanto inicial quanto continuada. Mesmo assim, algumas pesquisas têm apontado que, apesar dos esforços, pouco se tem avançado neste sentido. Gatti et al. (2019, p. 177) explicitam que:
No âmbito das políticas, destacam-se as críticas de desprofissionalização,

precarização e aligeiramento da formação, bem como a frágil articulação entre a formação inicial, a formação continuada, a inserção profissional e as condições de trabalho, salário e carreira dos profissionais da educação. E, no âmbito das práticas formativas, no contexto da formação inicial e continuada, as críticas dizem respeito principalmente à frágil articulação entre teoria e prática, entre conhecimento específico e conhecimento pedagógico, entre universidades e escolas.

Embora exista um movimento que vise à formação de professores diante do prescrito nos documentos oficiais, é notório que essas mudanças não são realmente significativas. A partir da análise de pesquisas publicadas a esse respeito, a autora identifica ainda a dissonância entre a teoria e prática presentes nos currículos de formação de professores - fato que faz com que a formação se torne incompleta.

A esse respeito, Gatti et al. (2019) analisaram algumas experiências que fossem realmente inovadoras do ponto de vista da formação inicial e continuada de professores, recorrendo a vários autores e pesquisadores de diversas regiões do país diante do que já se tem em termos de pesquisas neste campo. Após uma análise minuciosa de algumas dessas obras, Gatti et. al(2019, p. 212) apontam que :

Apesar de essa procura não ter assegurado procedimentos

sistematizados de busca, obteve-se parcas indicações. $\mathrm{Na}$ literatura disponível, também são escassos os estudos que investigam os avanços dos modelos de cursos de licenciatura e os efeitos das mudanças curriculares empregadas no contexto 
das reformas na formação inicial.

Apesar dessa escassez, existe um grande investimento em projetos dirigidos especificamente para qualificar a formação inicial de professores nas Instituições de Ensino Superior. Dentre elas, podemos destacar a modernização do Programa Institucional de Bolsas de Iniciação à Docência (PIBID) e o Programa de Residência Pedagógica (PRP) que, mesmo apresentando alguns problemas em sua execução, trazem resultados positivos, estimulandoestudantes a escolherem a docência e nela permanecerem, trazendo mais valorização a esses cursos no interior das instituições que os acolhem e implementam, gerando alterações curriculares em alguns casos (GATTI et.al 2019, $p$. 65 apud ANDRADE, 2011; APARÍCIO, 2011; PRADO, 2016).

Fica clara a preocupação das autoras com - caráter científico dos trabalhos produzidos nesta etapa dos Cursos de licenciatura em Matemática. A ausência de disciplinas que contemplem aspectos essenciais às exigências deste tipo de trabalho gera uma gama deatividadesdesconexas que não possibilitarão aos futuros professores a um ensino adequado para o ambiente escolar.

\section{CONSIDERAÇÕES FINAIS}

De modo geral, ainda que o currículo dos cursos de licenciatura em Matemática não apresente um distanciamento muito grande em relação aos conteúdosdos currículos oficiais da escola básica, é explicita a dicotomia entre teoria e práticapresente nesses cursos. As pesquisas acima relacionadas apontam uma deficiência muito grande, principalmente na relação entre o currículo específico, pedagógico e as atividades práticas e científico-culturais.

Diante das pesquisas supracitadas neste artigo, podemos concluir que, em geral, os cursos de licenciatura em Matemática trazem, mesmo que implicitamente, raízes do tradicional modelo " $3+1$ ". Essa conclusão se deve à desarticulação entre as disciplinas, contrariando o proposto pelas Diretrizes Curriculares que defendem a interdisciplinaridade - mesmo dividindo o currículo em eixos. Desse modo, oscursos de licenciatura assumem "ares" de bacharelado valorizando prioritariamente conteúdos específicos da Matemática restando pouco tempo para formação pedagógica, ou para atividades curriculares que integrem conteúdo matemático e atividades práticas que visem a apropriação de conhecimentos necessários à prática docente no ensino fundamental.

As pesquisas também evidenciam problemasno currículo de formação dos Cursos de Pedagogia. Existe, de forma mais latente, a dicotomia entre disciplinas da área das Ciências da Educação, Matemática e científico- culturais. Os conteúdos presentes nas disciplinas relacionadas à Matemática e/ou Educação Matemática não contemplamas orientações propostas pelas Diretrizes CurricularesNacionais,gerando uma deficiência muito grande para a prática desses futuros professores. Os apontamentos relacionados ao Estágio Supervisionado indicam a ineficácia dessas atividades diante da demanda do Curso de Pedagogia, caracterizado historicamente porseucaráter polivalente. Duas razões podem explicar tal deficiência:ocurso contempla concomitantemente conhecimentos, de várias áreas(Língua Portuguesa, Matemática, História, Geografia, Ciências), impossibilitando um acompanhamento integral e efetivo dos professores orientadores na realização destas atividades;os estágios, mesmo tendo início mais cedo nos cursos funcionam como apêndice e não como elemento articulador entre conteúdos pedagógicos e disciplinares no curso.

Em síntese,Saviani (2008) tece algumas críticas ao modelo de formação do pedagogo apresentado nas DCNPs/2006. Para o autor, o pedagogo é o profissional especialista na organização dos processos educativos, mas, diante do inchaço curricular no Curso de Pedagogia, defende a articulação entre a formação deste profissional e daquele que atuará nas séries iniciais do Ensino Fundamental, acrescentando:

[...] no caso da educação infantil e das séries iniciais do ensino fundamental estamos diante de professores integrados e não parcelados, como ocorre com as quatro 
últimas séries do Ensino Fundamental e no Ensino Médio, nos quais estamos diante de professores especializados no conteúdo, o que implica outro modelo de professor.[...] (SAVIANI, 2008, p. 647).

Por sua vez, Freitas (2019, p. 3-4) defendendo a Resolução CNE/CP 01 e 02/2015 e tece fortes críticas acercado atual quadro na formação de professores desde a implementação da BNCC pela Resolução CNE/CP 02/2019.Em entrevista, aponta que:

O atual alinhamento da Base Nacional Comum de Formação de Professores ao currículo da educação básica - a BNCC - nos permite afirmar que a formação passará a ser regulada pela Base Nacional Comum Curricular, e não pelos fundamentos científicos no campo das ciências da educação e das ciências pedagógicas e a produção de conhecimento da área educacional, que contemplam as relações entre escola, sociedade e trabalho, impactando sobre a organização da escola, do currículo, do percurso formativo, e da formação da infância, da juventude.

Assim, é importante a discussão acerca dos currículos de formação de professores de Matemática - pedagogos e licenciados em Matemática - a fim de maximizar positivamente os impactos que a formação tem sobre a prática desses professores.

\section{REFERÊNCIAS}

ALBUQUERQUE, L.; GONTIJO, C. A complexidade da formação do professor de matemática e suas implicações para a prática docente. Revista Espaço Pedagógico, Passo Fundo, v. 20, n. 1, p. 76-87, out. 2013. Disponível em:http://seer.upf.br/index.php/rep/article/view
13508. Acesso em

07 set. 2020.OI: 10.5335/rep.2013.3508

ANPED. Posição da ANPED sobre o "texto referência - diretrizes curriculares nacionais e base nacional comum para a formação inicial e continuada de professores da educação básica". Rio de Janeiro, 2019. Disponível em: https://anped.org.br/news/posicao-da-anpedsobre-texto-referencia-dcn-e-bncc-paraformacao-inicial-e-continuadade\#: :text=0\%20Texto\%20Refer\%C3\%AAncia\%20 sobre\%20as,os\%20pressupostos\%20subjacentes \%20a\%20BNCC. Acesso em: 07 set. 2020.

BATISTA, Alex Ribeiro. A formação inicial do professor de Matemática: a perspectiva dos formadores das licenciaturas de Presidente Prudente/SP. 2018. 294f. Dissertação (Mestrado em Educação) - Universidade Estadual Paulista, Faculdade de Ciências e Tecnologia, Presidente Prudente, 2018.

BRASIL. Conselho Nacional de Educação - CNE. Conselho Pleno. Parecer CNE/CP $n^{\circ}$ 3/2006. Institui as Diretrizes Curriculares Nacionais para o curso de graduação em pedagogia, homologado pelo MEC em 21 de fevereiro de 2006. Brasília, $2006 a$.

BRASIL. Ministério da Educação. Conselho Nacional de Educação. Conselho Pleno. Resolução CNE/CP n. 1 de $\mathbf{1 5}$ de maio de 2006. Institui Diretrizes Curriculares Nacionais para o curso de graduação em Pedagogia. Brasília: CNE, 2006b. Disponível em: http://portal.mec.gov.br/cne/arquivos/pdf/rcp00 6.pdf. Acesso em 07 set. 2020.

BRASIL. Ministério da Educação. Conselho Nacional de Educação.Parecer CNE/CES $1.302 / 2001$. Diretrizes curriculares nacionais para os cursos de matemática, bacharelado e licenciatura. Diário Oficial da União, Brasília, 05 mar. 2002a, Seção 1, p. 15. Disponível em: http://portal.mec.gov.br/cne/arquivos/pdf/CES1 3022.pdf. Acesso em: 07 set. 2020.

BRASIL. Ministério da Educação. Conselho Nacional de Educação. Parecer CNE/CP 9/2001, de 8 de maio de 2001a. Diretrizes Curriculares Nacionais para a Formação de Professores da Educação Básica, em nível superior, curso de licenciatura, de graduação plena. Diário Oficial 
da União, Brasília, DF, 18 de jan. 2002. seção 1. p.31. Disponível em: http://portal.mec.gov.br/cne/arquivos/pdf/009.p df. Acesso em: 07 set. 2020.

BRASIL. Ministério da Educação. Conselho Nacional de Educação. Resolução CNE/CP 1/2002, de 18 de fevereiro de 2002. Institui Diretrizes Curriculares Nacionais para a Formação de Professores da Educação Básica, em nível superior, curso de licenciatura, de graduação plena. Brasília, 2002. Disponível em: http://portal.mec.gov.br/cne/arquivos/pdf/rcp01 02.pdf. Acesso em: 07 set. 2020.

BRASIL.Ministério da Educação. Conselho Nacional de Educação. Resolução CNE/CP 2/2002, de 19 de fevereiro de 2002. Institui a duração e a carga horária dos cursos de licenciatura, de graduação plena, de Formação de Professores da Educação Básica em nível superior. Diário Oficial da União, Brasília, DF, 4 de mar de 2002, seção 1, p.9. Disponível em: http://portal.mec.gov.br/cne/arquivos/pdf/CP02 2002.pdf. Acesso em: 07 set. 2020.

BRASIL. Ministério da Educação. Resolução CNE/CP no 1, de 18 de fevereiro de 2002. Institui Diretrizes Curriculares Nacionaispara a Formação de Professores da Educação Básica, em nível superior, curso de licenciatura, degraduação plena. Brasília, 2002.Disponível em: http://portal.mec.gov.br/cne/arquivos/pdf/rcp01 02.pdf. Acesso em: 07 set. 2020.

BRASIL.Ministério da Educação. Resolução CNE/CP no 2, de 20 de dezembro de 2019. Define as Diretrizes Curriculares Nacionais para a Formação Inicial de Professores para a Educação Básica e institui a Base Nacional Comum para a Formação Inicial de Professores da Educação Básica (BNC-Formação). Brasília, 2019. Disponível em:

http://portal.mec.gov.br/index.php?option=com docman\&view=download\&alias=135951rcp002-19\&category slug=dezembro-2019pdf\&Itemid=30192. Acesso em: 07 set. 2020.

BRASIL. Resolução no 2, de 10 de julho de 2015. Define as Diretrizes Curriculares Nacionais para a formação inicial em nível superior (cursos de licenciatura, cursos de formação pedagógica para graduados e cursos de segunda licenciatura) e para a formação continuada. Brasília, 2015. Disponível em: http://pronacampo.mec.gov.br/images/pdf/res c ne cp 02 03072015.pdf. Acesso em: 07 set. 2020.

BRASIL. Ministério da Educação. Base Nacional Comum Curricular: EnsinoFundamental e Médio. Brasília: MEC/Secretaria de Educação Básica, 2018.

BRZEZINSKI, I.Pedagogia, pedagogos e formação de professores. Campinas: Papirus, 1996.

CURI, E. A formação matemática de professores de dois anos teve início no aspecto fundamental das novas demandas brasileiras. Revista Iberoamericana de Educação, v. 37, n. 5 p. 1-10, 25 de janeiro 2006. Disponível em https://rieoei.org/historico/deloslectores/1117Cu i. Acesso em: 07 set. 2020.

CURI, E. Formação de professores polivalentes: uma análise de conhecimentos para ensinar Matemática e de crenças e atitudes que interferem na constituição desses conhecimentos. 2004. 278 f. Tese (Doutorado em Educação) - Pontifícia Universidade Católica, São Paulo, 2004.

CYRINO, M. C. C. T.; PASSERINI, G. A. Reflexões sobre o estágio supervisionado do curso de Licenciatura em Matemática da Universidade Estadual de Londrina. In: CAINELLI; M.; FIORELI, I. (Orgs.). $O$ estágio na licenciatura: a formação de professores e a experiência interdisciplinar na Universidade Estadual de Londrina. Londrina: UEL/Prodocencia/Midiograf. p.125-144.

DOURADO, L. F. Diretrizes curriculares nacionais para a formação inicial e continuada dos profissionais do magistério da educação básica: concepções e desafios. Educação e Sociedade, Campinas, v. 36 , n. 131, p. 299324, Junho, $2015 . \quad$ Disponível em: http://www.scielo.br/scielo.php?script=sci arttex t\&pid=S0101-

73302015000200299\&Ing=en\&nrm=iso. Acesso em 07 set. 2020. DOI: 10.1590/ESO101$\underline{73302015151909}$

FIORENTINI, D.et al.Formação de professores que ensinam Matemática: um balanço de 25 anos da pesquisa brasileira. Dossiê: Educação 
Matemática. Educação em Revista, Belo Horizonte, v. 17, n. 36, p. 137-160, dez. 2002.

FREITAS, H. C. L.Entrevista concedida ao Portal EPSJV/Fiocruz [Entrevista concedida a] Ana Paula Evangelista, Julia Neves - EPSJV/Fiocruz. $2020 . \quad$ Disponível em: http://www.epsjv.fiocruz.br/noticias/entrevista/e la-nao-e-uma-proposta-inovadora-nao-olhaparadificuldades-atuais-no-campo-da. Acesso em: 20 Set. 2020.

GATTI, B. A.; NUNES, M. M. R. (Orgs.). Formação de professores para o ensino fundamental: estudo de currículos das licenciaturas em pedagogia, língua portuguesa, matemática e ciências biológicas. São Paulo: FCC, 2009.

GATTI, B. A. Formação de professores no Brasil: características e problemas. Educação e Sociedade, Campinas, v. 31 , n. 113, p. 13551379, dez. 2010. Disponível em: https://www.scielo.br/pdf/es/v31n113/16.pdf.

Acesso em: 07 set. 2020.DOI: 10.1590/S0101$\underline{73302010000400016}$

GATTI, B. A. et al.Professores do Brasil: novos cenários de formação. [S.I: s.n.], 2019.

LIBANEO, J. C. Diretrizes curriculares da pedagogia: imprecisões teóricas e concepção estreita da formação profissional de educadores. Educação e Sociedade, Campinas, v. 27, n. 96, p. 843-876, Out. 2006. Disponível em: http://www.scielo.br/scielo.php?script=sci arttex t\&pid=S0101-

73302006000300011\&lng=en\&nrm=iso. Acesso em: 07 set. 2020.DOI: 10.1590/S010173302006000300011

LORENZATO, Sérgio. Educação infantil e percepção matemática. 3.ed. Campinas, SP: Autores Associados, 2011.

MOREIRA, P.C. $3+1$ e suas (in)variantes: reflexões sobre as possibilidades de uma nova estrutura curricular na licenciatura em matemática. Bolema, Rio Claro, v. 26, n.44, p.1137-1150, dez. $2012 . \quad$ Disponível em: https://www.scielo.br/scielo.php?script=sci artte xt\&pid=S0103-

636X2012000400003\&lng=pt\&tlng=pt. Acesso em: 07 set. 2020. DOI: 10.1590/S0103$\underline{636 \times 2012000400003}$
PASSOS, C. L. B.; NACARATO, A. M. Trajetória e perspectivas para o ensino de Matemática nos anos iniciais. Estudos Avançados, São Paulo, v. 32, n. 94, p. 119-135, Dez. 2018 . Disponível em http://www.scielo.br/scielo.php?script=sci arttex t\&pid=S010340142018000300119\&lng=en\&nrm=iso. Acesso em: 21 Set. 2020.DOI: 10.1590/s0103$\underline{40142018.3294 .0010}$

PEREIRA, J. E. D. As licenciaturas e as novas políticas educacionais para a formação docente. Educação e Sociedade, Campinas, v. 20, n. 68, p. 109-125, Dec. 1999 . Disponível em:

http://www.scielo.br/scielo.php?script=sci arttex t\&pid=S0101-

73301999000300006\&lng=en\&nrm=iso. Acesso em: 20 Set. 2020. DOI: 10.1590/S0101$\underline{73301999000300006}$

PINTO, U. A.Pedagogia e Pedagogos Escolares. 2006. 184f. Tese (Doutorado em Educação) Universidade de São Paulo, São Paulo, 2006.

SACRISTÁN, J. G. O currículo: uma reflexão sobre a prática. Tradução de Ernani F. da F. Rosa. 3. ed. Porto Alegre: Artmed, 2000.

SÃO PAULO (Estado). Secretaria da Educação. Currículo do Estado de São Paulo: Matemática e suas Tecnologias. São Paulo, SEE, 2011.

SAVIANI, D.O curso de pedagogia e a formação de educadores (entrevista). Perspectiva (UFSC), Florianópolis, v. 26, p. 641-660, 2008.Disponível em:

https://periodicos.ufsc.br/index.php/perspectiva Larticle/view/2175-795x.2008v26n2p641. Acesso em: 07 set. 2020.

SILVA, Carmem Silvia Bissolida.Curso de Pedagogia no Brasil: história e identidade. 3.ed. Campinas, SP: Autores Associados, 2006. 